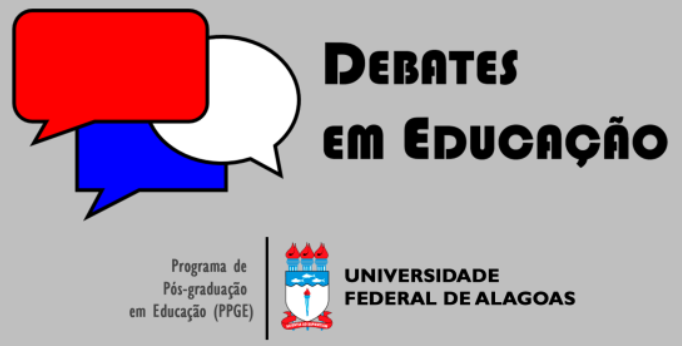

ISSN Eletrônico 2175-6600

Vol. I I | No. 23 | Jan./Abr. | 2019

Guilherme José Santini

(9)

Instituto Federal de Mato Grosso (IFMT) santinissilva@hotmail.com

Josiele Maiara Fuzinato

(9) iD

Instituto Federal de Mato Grosso (IFMT) josymaiara@hotmail.com

\section{ANÁLISE DO AUMENTO NO ÍNDICE DE DESENVOLVIMENTO DA EDUCAÇÃO BÁSICA (IDEB) EM ESCOLA PÚBLICA MUNICIPAL DE GUARANTÃ DO NORTE/MT NO PERÍODO 2007-2017}

\section{RESUMO}

trabalho que se segue tem por objetivo analisar o desempenho de uma instituição de ensino da rede municipal de Guarantã do Norte/MT no Índice de Desenvolvimento da Educação Básica (IDEB) ao longo do decênio 2007-2017, quando a escola teve um aumento superior à média projetada para o mesmo período, ano a ano. Tabelas foram utilizadas para proporcionar uma apresentação mais inteligível dos dados coletados, os quais são analisados a partir de três variáveis supostas hipoteticamente como causas desse bom desempenho ao longo desse período. São elas: i. aumento do repasse pelo PDDE à instituição; ii. proporção professor/aluno; iii. proporção de docentes efetivos. É um estudo de caso que pretende contribuir para uma reflexão sobre quais são os fatores que mais influenciam a qualidade do ensino oferecido por escolas públicas de Ensino Básico.

Palavras-chave: IDEB. INEP. Gestão da Educação.

\section{ANALYSIS OF THE INCREASE IN THE DEVELOPMENT INDEX OF BASIC EDUCATION (IDEB) IN A PUBLIC SCHOOL OF GUARANTÃ DO NORTE IN THE PERIOD 2007-20I7}

\begin{abstract}
The following work aims to analyze the performance of a public school of Guarantã do Norte/MT in the Index of Basic Education Development (IDEB) throughout the decade 2007-20 17, when the school had a higher increase to the projected average for the same period, year by year. Tables were used to provide a more intelligible presentation of the collected data, which are analyzed from three hypothetically assumed variables as causes of this good performance along this period: i. increase in the PDDE transfer to the institution; ii. teacher/student ratio; iii. proportion of effective teachers. It is a case study that intends to contribute to a reflection on which are the factors that most influence the quality of the teaching offered by public schools of Basic Education.
\end{abstract}

Keywords: IDEB. INEP. Education Management.

Submetido em: 04/12/2018

Aceito em: 04/04/2019

Ahead of print em: I I/04/2019

Publicado em: 25/04/2019

d.

http://dx.doi.org/l0.28998/2175-6600.2019v1 In23p284-298 


\section{INTRODUÇÃO}

O Brasil possui um baixo nível quanto ao quesito educação, que passou a poder ser acessado por todos os cidadãos somente em 1934 com a nova Constituição em vigor, a primeira após a Revolução de 1930 cujos líderes almejavam modernizar o Estado brasileiro. Antes disso, o acesso à educação regular era restrito, não garantida a obrigatoriedade de sua universalidade pelo Estado. Ou seja, mais de 100 anos após a Independência, a educação era direito de todos apenas virtualmente, pois não estava acessível a todos.

Hoje, às vésperas do Bicentenário da Independência, ainda nos defrontamos com óbices operacionais na tarefa pública em nome da garantia de uma educação de qualidade para todos os brasileiros em idade escolar. Operacionais, e não apenas financeiros, é o que queremos ressaltar de início. Cumpre prestar atenção também na gestão voltada à educação, suposto que toda gestão deve estabelecer metas e estratégias, a partir do conhecimento da situação real do ensino. Largos passos foram dados após a Constituição Cidadã de 1988. A partir de então, o Estado brasileiro procurou agir mais efetivamente na atenuação e solução de gargalos pontuais da educação brasileira, atuando em prol da garantia do amplo acesso à educação mesmo nas regiões mais remotas; da alfabetização também de jovens e adultos; da extinção da alfabetização; do fomento ao ensino básico atendendo a demandas de estados e municípios, entre outras frentes de atuação. E, tanto para conhecer a real situação do ensino oferecido em todos os níveis da federação, quanto para atualizar a partir dos resultados alcançados as suas próprias metas e estratégias, a avaliação do ensino passou a ser um tema de política de Estado, não só de governos. $\bigcirc$ Estado brasileiro passou a subsidiar dessa maneira a gestão da educação nas várias esferas e frentes de trabalho.

Um marco histórico nessa nova fase do Estado brasileiro em prol da educação que decidimos destacar, com respeito ao último item assinalado - a importância estratégica da avaliação do ensino - é o ano de 2007, quando o Ministério da Educação (MEC) lançou o Índice de Desenvolvimento da Educação Básica (IDEB), um índice objetivo para medir a qualidade do ensino nas escolas. O Estado brasileiro criou, com o IDEB, um termo universal de medida para a educação em escalas municipal, estadual e federal.

Não só este estudo pressupõe o IDEB como um índice de primeira importância na análise do desempenho das instituições de ensino. Na verdade, o próprio Estado brasileiro o pressupõe nessa magnitude de importância. Oficialmente, segundo o portal do INEP (20 I 8), o IDEB é uma iniciativa para mensurar o desempenho do sistema educacional brasileiro. Basicamente, essa mensuração é feita partir da combinação entre a proficiência obtida pelos estudantes em avaliações externas de larga escala (SAEB) e a taxa de aprovação, indicador que tem influência na eficiência do fluxo escolar, ou seja, na progressão 
dos estudantes entre etapas/anos na educação básica. Essas duas dimensões são refletidas pelo IDEB, mostrando quais são os problemas estruturais da educação básica brasileira; quais são as prioridades que a gestão do ensino deve reconhecer como tais para que o país alcance níveis educacionais compatíveis com seu potencial de desenvolvimento, agindo de maneira consequente com a garantia do direito à educação, tal como expresso em nossa Constituição Federal ${ }^{1}$, que fez o Estado brasileiro tomar para si a responsabilidade manifesta não apenas pela oferta de ensino, mas também pela sua promoção qualitativa, o que exige, como dito, uma gestão de qualidade, o que exige por sua vez, condicionalmente, um conhecimento aprimorado do real estado da educação nacional.

Portanto, diante do contexto apresentado, e pressuposto o IDEB como índice oficial para medir o desempenho educacional das instituições de ensino básico, o que nós pretendemos aqui é analisar a gestão escolar da Escola $A B C$ procurando encontrar quais foram os fatores responsáveis por seu bom desempenho no IDEB de 2007 a 2017.

Isso será feito por meio do levantamento e comparação de alguns dados da Escola ABC, referentes à quantidade de alunos, à relação de alunos por professor, e ao volume dos repasses financeiros municipais.

Qual ou quais teriam sido a(s) variável(eis) que podem ser reconhecida(s) como preponderante(s) para um melhoramento tão expressivo no IDEB da Escola $A B C$ ao longo desse período? Dito de outra maneira: entre essas variáveis observadas, qual ou quais teriam sido aquela(s) que pode ser considerada a a(s) causa(s) do aumento expressivo que a escola teve na nota do IDEB de 2007 a 20 I 7? Esta é a questão a que procuramos responder e que define o fio condutor deste trabalho.

Os dados coletados foram obtidos na Escola ABC, na Secretaria de Educação do Município de Guarantã do Norte, e também no site do INEP, para verificação das variáveis ao longo do período estudado. Foram distribuídos em tabelas, de acordo com cada fator citado, em perspectiva comparada.

\section{DESENVOLVIMENTO}

Vejamos a seguir como funcionam alguns dos principais exames que servem como índices de qualidade da Educação Básica no Brasil, para em seguida partir para o estudo do caso da Escola ABC que

\footnotetext{
' Citamos textualmente três artigos da Constituição Federal onde o tema da educação é destacado, incluindo expressamente a atenção com as exigências da inclusão, do amplo acesso e da qualidade do serviço oferecido - os artigos 205, 206 e 208. Diz o texto constitucional: "Art. 205. A educação, direito de todos e dever do Estado e da família, será promovida e incentivada com a colaboração da sociedade, visando ao pleno desenvolvimento da pessoa, seu preparo para o exercício da cidadania e sua qualificação para o trabalho"; "Art. 206. O ensino será ministrado com base nos seguintes princípios: I - igualdade de condições para o acesso e permanência na escola"; "Art. 208. O dever do Estado com a Educação será efetivado mediante a garantia de: III - atendimento educacional especializado aos portadores de deficiência, preferencialmente na rede regular de ensino". Cf. BRASIL. Constituição Federal de 1988. Brasília: Senado Federal, 1988. Promulgada em 05 de Outubro de 1988. Disponível em: http://www.planalto.gov.br/ccivil_03/Constituicao/Constituicao67.htm.
} 
vem a ser o objeto deste artigo, já que o destaque merecido ao desempenho da Escola $A B C$ se deve a seu bom desempenho em um desses índices.

\section{I SAEB, PROVA BRASIL E IDEB}

Na década de 90, já sob a vigência da "Constituição Cidadã", os deveres assumidos pelo Estado brasileiro em relação à educação geraram uma demanda no sentido de monitorar o desempenho da educação nacional. Viu-se a necessidade de criar mais índices por meio dos quais a própria sociedade pudesse conhecer, transparentemente, como tem sido oferecido a educação, nomeadamente no ensino básico; ou seja, se o direito a uma educação qualitativamente consequente à plenitude do exercício da cidadania tem sido respeitado pelo Estado. Tendo em vista essa finalidade, o Ministério da Educação (MEC) lançou nos anos 90 o Sistema Nacional de Avaliação da Educação Básica (SAEB).

Segundo dados do INEP², ele é composto por um conjunto de avaliações externas em larga escala que permitem ao próprio INEP realizar um diagnóstico da educação básica brasileira e de alguns fatores que possam interferir no desempenho do estudante, fornecendo um indicativo sobre a qualidade do ensino ofertado.

De acordo com Rigotti; Cerqueira (20।5):

A preocupação em ampliar o conhecimento sobre a realidade do sistema educacional brasileiro, em seus diversos aspectos, tem levado o INEP a desenvolver outros estudos que possam servir de base para a elaboração de políticas públicas na área de educação, como é o caso do Sistema Nacional de Avaliação da Educação Básica (SAEB). (RIGOTTI; CERQUEIRA, 20 I 5, p.5).

Desde a sua criação, o SAEB passou por transformações que não podemos deixar de expor aqui. Já na primeira década do século XXI, precisamente em 2005, ele passou a ser composto por duas avaliações: Avaliação Nacional da Educação Básica (ANEB) e pela Avaliação Nacional do Rendimento Escolar (ANRESC), atualmente mais conhecida como Prova Brasil. Em 2013, um exame chamado Avaliação Nacional de Alfabetização (ANA) foi integrado ao SAEB. As principais avaliações do Ensino Básico deverão ser reconhecidas por essa sigla, SAEB; sendo que a aplicação das provas será realizada nos anos ímpares e a divulgação dos resultados nos anos pares.

\footnotetext{
${ }^{2}$ O INEP é o Instituto Nacional de Estudos e Pesquisa Educacionais Anísio Teixeira. É uma autarquia federal vinculada ao MEC datada de 1937 que é responsável até hoje, como está exposto em seu nome, pela avaliação da educação nacional. Assim, cumprindo com sua finalidade, é o INEP a instituição responsável, por exemplo, pelas provas do ENEM, do ENADE e pelas avaliações das instituições de ensino que oferecem, em território nacional, cursos de ensino básico e superior. O INEP se tornou, portanto, a instituição referencial para verificar dados com os quais se possa observar se os cidadãos têm obtido um serviço educacional a contento daquilo que a lei exige pelo próprio texto constitucional como vimos em nota anterior. Por causa de sua finalidade e missão, o INEP também é a grande fonte dos dados relacionados ao IDEB, já que é ele mesmo o órgão responsável por seu cálculo.
} 
As avaliações diagnósticas representadas pela Prova Brasil em 1990 eram compostas por: Língua Portuguesa, Matemática, Ciências Naturais, Redação - para o público-alvo da Ia $, 3^{\mathrm{a}}, 5^{\mathrm{a}}$ e $7^{\mathrm{a}}$ séries do ensino fundamental, e aplicadas em apenas algumas escolas públicas, ou seja, segundo um conjunto amostral reduzido, mas que pudesse servir de parâmetro mínimo para a situação real da educação no Brasil como um todo. Ou seja, de início o SAEB já não possuía uma universalidade do ponto de vista de sua aplicação. Ainda na década de 90, mais precisamente em 1995, o Ministério da Educação determinou que os exames fossem aplicados a cada dois anos e questionários também passaram a ser aplicados acerca de dados contextuais. Em 1997, começaram a ser avaliados alunos da $4^{\mathrm{a}}$ e $8^{\mathrm{a}}$ séries do ensino fundamental e da $3^{\mathrm{a}}$ série do ensino médio. Algumas escolas particulares também passaram a ser avaliadas. Além disso, as áreas de avaliação de conhecimento foram ampliadas, bem como a base amostral. As disciplinas que passaram a ser avaliadas foram: Língua Portuguesa, Matemática, Ciências Naturais, Física, Química e Biologia. Em 1999, entram, entre as disciplinas avaliadas, História e Geografia. Até que, a partir do ano de 2000, a avaliação diagnóstica se concentrou sobre as disciplinas de Língua Portuguesa e Matemática, mantendo sua aplicação para alunos da $4^{\mathrm{a}}$ e $8^{\mathrm{a}}$ série do ensino fundamental e da $3^{\mathrm{a}}$ série do ensino médio.

Em 2005, integradas a essas avaliações focadas no desempenho discente no ensino básico, outras modalidades avaliativas foram executadas, de natureza censitária, permitindo a divulgação dos resultados por municípios e por escolas, ampliando assim as possibilidades de análise dos resultados da avaliação e o escopo da leitura diagnóstica sobre a realidade da educação em diferentes escalas de observação. Nasceu, assim, a Prova Brasil, que utiliza os mesmos procedimentos utilizados pelo SAEB (BRASIL, 2008, p. I3), mas com essa finalidade mais censitária.

A Prova Brasil é composta por 21 cadernos de provas diferentes para cada série/ano, sendo que cada aluno responde apenas um caderno de prova. Segundo o INEP, cada caderno de prova é constituído por quatro blocos, sendo que dois são destinados a respostas de Língua Portuguesa e os outros dois abordam questões de Matemática. Os testes são de múltipla escolha. Os alunos de $5^{\circ}$ ano respondem a 22 itens de português e a 22 itens de matemática. Já os estudantes de $9^{\circ}$ ano e do $3^{\circ}$ ano do ensino médio respondem a 26 itens de português e a 26 de matemática. Note-se assim que a Prova Brasil diz respeito a habilidades e competências mais vinculadas a linguagens e a cálculos.

O ponto a destacar é que a Prova Brasil visa, além do diagnóstico do ensino enquanto tal, proporcionar referências censitárias sobre o ensino básico, significando assim nada mais que o cumprimento do Decreto No 6.094, de 24 de abril de 2007. Art. 2, cap. I, que diz:

Art. 2으 A participação da União no Compromisso será pautada pela realização direta, quando couber, ou, nos demais casos, pelo incentivo e apoio à implementação, por Municípios, Distrito Federal, Estados e respectivos sistemas de ensino, das seguintes diretrizes: I - estabelecer como foco a aprendizagem, apontando resultados concretos a atingir. 
Finalmente, em 2007, o Instituto Nacional de Estudos e Pesquisas Educacionais Anísio Teixeira (INEP) criou o IDEB, Índice de Desenvolvimento da Educação Básica, para servir, com base na Prova Brasil e no SAEB, de termo de medida nacional acerca da qualidade da educação no Ensino Básico - por instituição, por município, por Estado e nacionalmente. O IDEB é um índice, e não uma prova, portanto. Como índice ou termo de medida, ele é calculado a partir do SAEB (no caso dos IDEB dos Estados e também o nacional) e da Prova Brasil (para IDEB de escolas e municípios). Por causa da abrangência que o IDEB consegue ter em virtude do alcance do SAEB e da Prova Brasil, o IDEB é, digamos assim, o índice dos índices para medir a qualidade da educação no Ensino Básico.

Segundo Soares; Xavier (20|3):

Um dos motivos da grande respeitabilidade que o ldeb obteve é o fato de agregar, em um único indicador, uma medida de desempenho e outra de rendimento, dimensões fundamentais para uma análise relevante de sistemas de educação básica (SOARES; XAVIER, 20 I3, p.4).

Ligado ao SAEB, que desenvolve as Matrizes de Referências, tendo por base os Parâmetros Curriculares Nacionais (PCN) e os currículos praticados pelas secretarias municipais e estaduais de educação desde 1997, o IDEB representa como está o desempenho de alunos ligados a um amplo escopo de habilidades e competências teóricas. Isso porque as Matrizes de Referências contempladas pelo SAEB apresentam uma "descrição das competências e habilidades que os alunos deveriam dominar em cada série avaliada, permitindo uma maior precisão técnica tanto na construção de itens do teste como na análise dos resultados da avaliação." (BRASIL, 20II, p. 9). Cada matriz apresenta certos temas, que expressam associação entre os conteúdos curriculares e operações mentais desenvolvidas pelos alunos. Traduzem, por isso, certas habilidades e competências e geram os itens que compõem os testes.

E se, além do SAEB, o IDEB também é composto pela Prova Brasil, que possui uma finalidade mais censitária, uma vez que é aplicado em escolas que atendem à demanda pela educação nos níveis fundamental e médio por todo o país, o IDEB serve para acompanhar, como o próprio nome diz, o desenvolvimento do Ensino Básico, no que diz respeito a sua qualidade, segundo as Matrizes de Referências, e proporcionando interpretações dos dados em escalas municipal, estadual e nacional.

Dessa maneira, além da observação do êxito do ensino em escala nacional, o MEC pode verificar pelo IDEB a deficiência do ensino em escala local também, e assim apontar melhorias necessárias na educação oferecida em cada localidade, de maneira pontual, seja através de repasses, seja em forma de incentivos à qualificação dos professores.

Outro ponto positivo no IDEB é a sua periocidade, que permite fazer projeções e observar se as melhorias propostas foram eficientes ou não dentro de certas etapas temporais. Paro (200 I), por exemplo, acentua essa vantagem do IDEB, logo que diz: 
Em educação, é pela realização de um bom processo que se podem aumentar as probabilidades de realização de um bom produto; daí a importância da constante e adequada avaliação desse processo (PARO, 200 I, p. 39).

Se, como defende Paro (200 I), as avaliações diagnósticas são indispensáveis para averiguar a qualidade na educação e poder constatar gargalos a resolver pontualmente, ou senão criar estratégias mais gerais, o IDEB está estabelecido como um termo de medida central na educação brasileira. Garcia (2007) é outro estudioso que assevera ser esse índice um paradigma de avaliação em educação. Por meio dele, - MEC e os governos dos diferentes entes da Federação se tornam mais capazes de detectar o desempenho das escolas de ensino básico.

\subsection{O DESEMPENHO DA ESCOLA ABC NO IDEB DE 2007 A 2017}

De acordo com o Censo do MEC de 2017 a escola em estudo (ABC - nome fictício) possui: I3 salas de aulas, 45 funcionários, sala de diretoria, sala de professores, laboratório de informática, sala de recursos multifuncionais para atendimento educacional especializado (AEE), cozinha, biblioteca, parque infantil, banheiro dentro do prédio, banheiro adequado aos alunos com deficiência ou mobilidade reduzida, sala de secretaria, refeitório, almoxarifado.

No último IDEB, pertinente ao ano de 2017, a escola teve uma nota excelente - 7, I -, tornandose assim um case de sucesso na educação pública e em nível municipal. $\bigcirc$ que nos importa, em prol da ciência da gestão pública, é investigar: como isso foi possível? Ou, mais exatamente, investigar a(s) causa(s) do ótimo desempenho dessa instituição de ensino pública, consequência de um trabalho que não se restringe ao ensino, não sendo o fenômeno do ótimo desempenho de uma instituição de ensino pública objeto de interesse exclusivo para a Pedagogia, mas para a Gestão Pública também e igualmente.

Para efeitos comparativos, a meta do IDEB estipulada para o Brasil até 2021 é 6,0. Para Fernandes (2007):

A definição de uma meta nacional para o IDEB em 6,0 significa dizer que o país deve atingir em
2021 , considerando os anos iniciais do ensino fundamental, o nível de qualidade educacional, em
termos de proficiência e rendimento (taxa de aprovação), da média dos países desenvolvidos
(média dos países membros da OCDE) observada atualmente. Essa comparação internacional foi
possível devido a uma técnica de compatibilização entre a distribuição das proficiências observadas
no PISA (Programme for Internacional Student Assessment) e no SAEB. (FERNANDES, 2007, p.
2).

Até 2015 , segundo dados do INEP, apenas 6\% das escolas do Brasil conseguiram alcançar nota 7 no segmento referente às series iniciais do nível fundamental, e entre elas se encontra a Escola $A B C$, que teve em 2015 uma média de 7,2. Em 2005, primeiro dado disponível anterior ao IDEB - que é de 2007 -, apenas 6 escolas brasileiras dentro da amostragem atingiram a nota 7; sendo que em 2015, 10 anos 
após os primeiros dados, foram 2.138 escolas. Entretanto, ainda que tenha havido um progresso no desempenho educacional verificado nesse período, o número de escolas acima da média desejável ainda é pequeno em relação ao volume de escolas públicas brasileiras. Segundo o último Censo Escolar da Educação Básica, divulgado pelo INEP³, atualmente há I 84, I mil escolas de Ensino Básico no Brasil - das quais 1 | 2,9 mil são de responsabilidade dos municípios. Fica claro como o desempenho educacional, embora tenha progredido em uma década, ainda carece de políticas públicas e estratégias funcionais racionalmente estabelecidas a partir de amplos estudos de caso, a fim de se tornar satisfatório, em escala nacional.

Voltando ao caso da Escola ABC, tendo sido alcançada ali, no IDEB de 2017, uma nota 7,I nas séries iniciais do nível fundamental e 6,2 nas séries finais, cumpre destacar, como veremos a seguir, que não apenas se alcançou o mínimo desejado pelo MEC, como se ultrapassou a meta, tendo a Escola ABC alcançado uma posição de destaque em termos nacionais. Como isso foi possível, se uma década antes, em 2007, o IDEB da mesma escola foi de 5, I nas séries iniciais e de 3,6 nas séries finais? Responde a essa pergunta com base empírica, por meio de dados em perspectiva comparada, significa entender como esse êxito educacional foi possível, cujas condições podem ser reproduzidas em outras escolas municipais.

\section{$2.3 \quad$ RESULTADOS E DISCUSSÕES}

Vejamos os dados. Até o ano de 2017 a Escola ABC contava com 66 I alunos e com 29 docentes, na última avaliação do IDEB no ano de 2017 teve uma pontuação de 7,4 para séries iniciais e 6,2 para séries finais - sendo que a meta para o Estado do Mato Grosso para esse mesmo ano e segmento foi de 5, I . A tabela seguinte demonstrará a pontuação do IDEB na escola em questão nos anos analisados.

Tabela I - IDEB da Escola ABC do ano de 2007 a 2017

\begin{tabular}{cccccc}
\hline \multicolumn{5}{c}{$4^{\circ} / 5^{\circ}$ ano } & \multicolumn{3}{c}{$8^{\circ} / 9^{\circ}$ ano } \\
\hline Ano & IDEB observado & Metas projetadas & Ano & IDEB observado & Metas projetadas \\
\hline 2005 & 3.4 & & 2005 & 2.7 & \\
2007 & 5.1 & 3.5 & 2007 & 3.6 & 2.8 \\
2009 & 5.6 & 3.8 & 2009 & 4.7 & 3.1 \\
2011 & 6.3 & 4.1 & 2011 & 5.3 & 3.6 \\
2013 & 6.8 & 4.5 & 2013 & 5.5 & 4.2 \\
2015 & 7.2 & 4.8 & 2015 & 6.0 & 4.7 \\
2017 & 7.4 & 5.1 & 2017 & 6.2 & 4.9 \\
\hline
\end{tabular}

Fonte: http://ideb.inep.gov.br/resultado/resultado/resultado.seam?cid=195457|

3 Os dados podem ser acessados on-line pelo portal: http://censobasico.inep.gov.br/censobasico. Acessado em 28 de Novembro de 2018 
De acordo com a tabela I, a pontuação da Escola ABC em 12 anos (2005 a 2017) aumentou I 17,6\% para $4^{\circ} / 5^{\circ}$ e em 129,6\% para o $8^{\circ} / 9^{\circ}$ ano do ensino fundamental.

Segundo Assis; Amaral (2016, p. 206), o IDEB passou a significar o instrumento que indica a qualidade da educação básica brasileira, "servindo ainda para a montagem de rankings de escolas e de estados da federação".

A Escola ABC em 2017 teve $100 \%$ de rendimento escolar - o que alavanca o resultado, visto que esse é a soma das notas das provas e do rendimento escolar.

O que é "rendimento escolar"? O INEP usa como indicador de rendimento escolar para o IDEB a razão entre o número de anos de cada etapa e o número de ano que um aluno leva para completar uma série. Conforme expõem a esse respeito Soares; Xavier:

Ao fim de um ano letivo, cada aluno matriculado, que não foi formalmente transferido ou faleceu, é colocado em urna de três categorias. Na categoria de aprovados são classificados os alunos que, ao final do ano letivo, preencheram os requisitos mínimos de desempenho e frequência, previstos em legislação. Os reprovados são os alunos que, ao final do ano letivo, não preencheram os requisitos mínimos de desempenho e/ou frequência previstos em legislação. Os alunos que deixaram de frequentar a escola, tendo sua matrícula cancelada, são classificados na categoria de abandono (SOARES; XAVIER, 20I3, p. 08).

Desse modo, para uma escola alcançar o feito de 100\% de rendimento escolar, não pode haver nenhum aluno reprovado e nenhum caso de abandono escolar. Ou seja, a Escola ABC teve êxito em todo esse processo, que demanda um acompanhamento diuturno e maximamente responsável sobre os alunos e em articulação com os pais e a comunidade externa.

A Tabela 2, a seguir, demonstra a quantidade de alunos e docentes por ano letivo, bem como a quantidade de professores efetivos.

Tabela 2 - Quantidade de alunos e professores de 2007 a 2017

\begin{tabular}{cccc}
\hline Ano Letivo & Quantidade alunos & Quantidade de docentes & Quantidade de docentes efetivos \\
\hline 2007 & 498 & 22 & 17 \\
2008 & 543 & 24 & 23 \\
2009 & 521 & 24 & 22 \\
2010 & 528 & 24 & 23 \\
2011 & 537 & 24 & 25 \\
2012 & 583 & 29 & 27 \\
2013 & 583 & 29 & 30 \\
2014 & 583 & 29 & 32 \\
2015 & 620 & 31 & 29 \\
2016 & 680 & 31 & 29 \\
2017 & 661 & 29 & 30 \\
\hline
\end{tabular}

Fonte: http://www.educacenso.inep.gov.br/censobasico 
Analisando a tabela 2, verifica-se também outro dado relevante para nossa pesquisa: que houve um aumento de alunos, porém, que a quantidade de docentes não sofreu muita variação. Ou seja, a relação entre o número de docentes por aluno diminuiu, o que significa em tese mais alunos em sala de aula para cada professor poder assistir pedagogicamente, isto é, uma piora, em tese, das condições de trabalho. Inclusive, no ano em que a nota do IDEB foi maior, a quantidade de docentes foi menor do que a do ano de 2015 - e mesmo assim a nota da escola aumentou.

Identificou-se também, ao analisar a tabela, que a quantidade de professores efetivos no ano de 2017 foi bem superior ao ano de 2007, quando apenas 77,27\% dos docentes eram efetivos. $\bigcirc$ aumento do número dos docentes efetivos nas escolas tem um papel importante na formação do aluno, pois o professor cria vínculos com a escola, sente-se parte dela, e desse modo desenvolve melhor o seu trabalho, a partir de uma circunstância laboral que o faz ter mais sentimento de pertença em relação à instituição de ensino e à comunidade externa e a assumir uma identidade mais específica como servidor público.

Outro fator importante para que uma escola obtenha bom desempenho são os recursos que lhes são repassados. Em 1995, foi criado o Programa Dinheiro Direto na Escola (PDDE) para prestar assistência financeira às escolas públicas e privadas de educação especial mantida por entidades sem fins lucrativos, com o intuito de melhoria na infraestrutura física e pedagógica, deste modo podendo elevar os índices de educação básica. A Tabela 3 apresenta os repasses do PDDE à Escola ABC, de 2009 a 20 17:

Tabela 3 - Repasses do PDDE à Escola ABC:

\begin{tabular}{lc}
\hline Ano & Valor total de repasses $^{4}$ \\
\hline 2009 & $\mathrm{R} \$ 74.056,10$ \\
2010 & $\mathrm{R} \$ 93.109,40$ \\
2011 & $\mathrm{R} \$ 93.853,50$ \\
2012 & $\mathrm{R} \$ 92.734,13$ \\
2013 & $\mathrm{R} \$ 111.800,00$ \\
2014 & $\mathrm{R} \$ 106.300,00$ \\
2015 & $\mathrm{R} \$ 108.240,00$ \\
2016 & $\mathrm{R} \$ 104.320,00$ \\
2017 & $\mathrm{R} \$ 112.020,00$
\end{tabular}

Fonte: https://www.fnde.gov.br/pls/internet_pdde/internet_fnde.pdderex_2_pc

A tabela 3 mostra que houve um aumento nos repasses do PDDE à Escola ABC durante os anos estudados. Indubitavelmente, o repasse do PDDE às escolas é essencial para a sua manutenção. Segundo Almeida (2009), tratando especificamente sobre a importância financeira do PDDE:

O dinheiro do PDDE pode ser aplicado na aquisição de materiais permanentes (como bebedouro, impressora, aparelhos de ar condicionado etc.) e de itens de uso diário (papel, lápis,

${ }^{4}$ O valor total de repasses é a soma do valor de custeio e do valor de capital que foram repassados nos respectivos anos. 
caneta, borracha, cartuchos de tinta para impressora, produtos de limpeza, papel higiênico, sabonete etc.), na realização de pequenos reparos na infraestrutura física do prédio (como consertos de torneiras) e na contratação de mão de obra para esses serviços, nos materiais necessários para a implantação do Projeto Político Pedagógico, em instrumentos que permitam avaliar a aprendizagem e no desenvolvimento de atividades educacionais (ALMEIDA, 2009).

Importante mencionar que a verba do PDDE é repassada de acordo com o número de alunos as escolas, por uma conta criada pelo Fundo Nacional de Desenvolvimento da Educação (FNDE), cujo orçamento é parte do orçamento geral do MEC e que tem como finalidade fazer com que a União possa atender também às demandas educacionais de Estados e municípios, em uma ação subsidiária em prol do melhoramento do serviço educacional prestado por instituições públicas de todos os entes federativos.

Contudo, embora tenha havido esse repasse efetivamente, e ainda que ele tenha aumentado, a tabela 4 permite averiguar se esse aumento foi real ou meramente nominal. Para averiguá-lo, na tabela 4 comparamos os repasses feitos à Escola ABC, ano a ano, de 2007 a 20 I 7, com a variação respectiva Índice Geral de Preços no Mercado (IGP-M). Assim, se torna possível averiguar se os repasses aumentaram apenas em uma razão nominal, quer dizer, meramente numérica, ou se houve um aumento real, ou seja, superior à variação de um dos principais índices referentes a esse índice da inflação.

Tabela 4 - Aumento real do valor de repasse a escola $A B C$

\begin{tabular}{cccc}
\hline Ano & IGP-M & Ano & Aumento real do repasse à Escola ABC \\
\hline 2007 & $7,74 \%$ & 2007 & ----- \\
2008 & $9,80 \%$ & 2008 & ---- \\
2009 & $-1,71 \%$ & 2009 & ----- \\
2010 & $11,32 \%$ & 2010 & $-4,3 \%$ \\
2011 & $5,09 \%$ & 2011 & $-9 \%$ \\
2012 & $7,81 \%$ & 2012 & $14,98 \%$ \\
2013 & $5,52 \%$ & 2013 & $-8,58 \%$ \\
2014 & $3,67 \%$ & 2014 & $-8,71 \%$ \\
2015 & $10,54 \%$ & 2015 & $-10,81 \%$ \\
2016 & $7,19 \%$ & 2016 & $7,91 \%$ \\
2017 & $-0,53 \%$ & 2017 &
\end{tabular}

Fonte: http://www.portalbrasil.net/igpm.htm

Da descrição exposta na tabela 4 dos valores do PDDE repassados à Escola $A B C$, verificados segundo a variação respectiva anual do IGP-M, se constata que o aumento do repasse à Escola ABC não progrediu em termos reais. Com efeito, houve apenas um aumento nominal, significando um déficit no volume efetivo de repasses financeiros da União, via PDDE, à Escola ABC.

\footnotetext{
${ }^{5}$ Cálculo realizado com o repasse do PPDE e o IGP-M de cada ano, no qual pode ser verificado que não houve aumento no repasse do PDDE, pelo contrário, quando se calcula a média desses 8 anos, está fica em -8,83\%.
} 
Cumpre considerar, portanto, que o ótimo desempenho da Escola ABC no IDEB de 2007 a 2017 não pode ser respondido pelo aumento dos repasses do PDDE, que foi apenas nominal, significando que a escola teve em 2017 menos recursos repassados pela União do que em 2007; que as condições de trabalho dos docentes, em tese, se tornaram piores, com o aumento do número de alunos por professor; e que, entre as variáveis observadas, somente o número proporcional de docentes efetivos em relação ao quadro geral de docentes efetivamente aumentou para melhor.

\section{CONCLUSÃO}

Das variáveis quantitativas adotadas para a verificação do aumento do índice IDEB na escola ABC, apenas uma teve uma variação significativa no período estudado, de 2007 a 2017 . Apenas a proporção de docentes efetivos, ou seja, aprovados por concurso, pode servir para explicar como esse aumento ocorreu. As outras variáveis, pelos dados recolhidos - repasses da União à Escola ABC pelo PDDE via FNDE e a relação docentes/alunos -, demonstram que, exceção feita a esse item referente ao quesito do status funcional dos servidores docentes, as condições financeiras e de trabalho dos docentes se depreciaram, o que é incongruente com o fenômeno do crescimento do IDEB de 5, I em 2007 para 7,4 em 2017.

A variável da proporção do número de docentes efetivos se mostra um indicador relevante para interpretar o fenômeno do aumento da qualidade do serviço educacional prestado pela Escola ABC.

Ora, essa variável diz respeito a um fator que não foi mencionado, mas é a condição sem a qual não há planejamento do pessoal aplicado à educação diretamente. Esse fator é a Gestão Pública. Convém assinalar que o aumento do número de docentes efetivos demanda, previamente, o planejamento feito pela gestão municipal e não apenas escolar - referente, por exemplo, ao controle da folha de pagamento do município tendo em conta as previsões da arrecadação para os anos seguintes. Se entre as variáveis analisadas, aquela que estaria mais diretamente relacionada como causa do bom desempenho da Escola ABC no IDEB de 2007 a 2017 é o aumento da proporção de docentes efetivos, esse fato não teria ocorrido sem um planejamento estratégico institucional, tarefa inerente à Gestão Pública. Em outras palavras, a Gestão Pública seria o fator causador primeiro, a causa causante, e o aumento da proporção de docentes efetivos a causa causada do fenômeno do bom desempenho progressivo da Escola ABC no IDEB de 2007 a 2017.

E, com efeito, a Gestão Pública é um fator que aparece no debate sobre estratégias para a educação brasileira. Paro (2007), por exemplo, apresenta a Gestão Pública como um dos condicionantes da qualidade de ensino. Pressuposto a Gestão Escolar como um ramo da Gestão Pública, o autor defende 
que o modo como a escola funciona e seu diálogo com os agentes executivos superiores influem consequentemente na qualidade do serviço oferecido pelas instituições de ensino públicas, podendo contribuir ou piorar o bom desempenho educacional do país. As ações e escolhas dos gestores interferem decisivamente na qualidade educacional, não sendo a responsabilidade por esta última um assunto exclusivo de docentes em sala de aula ou um tema de interesse exclusivo de pedagogos.

Sem dúvida, são vários os fatores que interferem na gestão escolar, como: as relações entre discentes e docentes, as estratégicas pedagógicas escolhidas pelas coordenações de cursos, as técnicas de avaliação discente, o clima de trabalho na instituição, a organização do trabalho coletivo, etc. Mas há que se ter em conta - é o que defendemos à guisa de conclusão - como é determinante o planejamento inerente à Gestão Pública para o bom desempenho do Ensino Básico; que a Gestão Pública, ainda quando não trata diretamente da educação - quando, por exemplo, planeja e administra a folha de pagamento dos servidores, diante de metas referentes a um aumento da proporção de servidores docentes que sejam efetivos - deve ser reconhecida como um fator condicionante para o bom desempenho da educação pública, principalmente quando se tem em conta instituições de ensino municipais, dada a maior suscetibilidade do orçamento municipal - e, via de regra, das instituições de ensino municipais - a variações orçamentárias e financeiras.

Também Libâneo (2008) frisa a importância da Gestão Pública, corroborando nossa reflexão. Falando a respeito desse assunto, o autor esclarece que "o modo como a escola funciona - suas práticas de organização e gestão - faz diferença em relação aos resultados escolares". (2008, p. 10). Assim sendo, Levando em consideração as referências teóricas de Paro (2007) e Libâneo (2008) sobre a importância em potencial da gestão na prática do ensino a partir da análise dos dados que expusemos da Escola ABC, podemos concluir que, de fato, no caso do aumento expressivo do bom desempenho educacional dessa instituição, há razão suficiente para se afirmar que ali o trabalho da Gestão Pública, especialmente em relação à expansão da proporção de servidores públicos efetivos no corpo docente da escola, pode ser considerado um fator decisivo para que se obtivesse um conjunto de causas que proporcionasse, por sua vez, o êxito dessa escola em sua finalidade própria, que é oferecer um ensino de qualidade a seus alunos no Ensino Básico, mais exatamente no ensino fundamental.

\section{REFERÊNCIAS}

ALMEIDA, Daniela. 5 pontos sobre Programa Dinheiro Direto na Escola. 2009. Disponível em: https://gestaoescolar.org.br/conteudo/7 I //5-pontos-sobre-programa-dinheiro-direto-na-escola. Acesso em: $21 / 1$ I/2018. 
ASSIS, Lúcia Maria de; AMARAL, Nelson Cardoso. Avaliação da Educação: por um sistema nacional. In: DOURADO, Luiz Fernandes; AZEVEDO, Janete Marai Lins de. (Org.) Relações Federativas e Sistema Nacional de Educação. Camaragibe: CCS Gráfica e Editora, 20 I6, p. 205-245

BRASIL. Constituição Federal (1988). Brasília: Senado Federal, 1988. Disponível em: http://www.planalto.gov.br/ccivil 03/Constituicao/Constituicao.htm. Acesso em 21 nov. 2018.

BRASIL. Ministério da Educação. PDE: Plano de Desenvolvimento da Educação: Prova Brasil: ensino fundamental: matrizes de referência, tópicos e descritores. Brasília: MEC, SEB; Inep, 2008.

BRASIL. Decreto 6.094 de 24/04/2007. Dispõe sobre a implementação do Plano de Metas Compromisso Todos pela Educação. Brasília, DF, abril de 2007. Disponível em: http://www.planalto.gov.br/ccivil_03/_ato200720 10/2007/decreto/d6094.htm. Acesso em: 12 nov. 2018.

BRASIL. Índice de Desenvolvimento da Educação Básica. 20 18. Disponível em: http://idebescola.inep.gov.br/ideb/escola/dadosEscola /51007770. Acesso em: 04 out. 2018.

BRASIL. EDUCACENSO 2018. Disponível em: http://www.educacenso.inep. gov.br/censobasico/\#/. Acesso em 08 nov. 2018.

BRASIL. Sistema Nacional de Avaliação da Educação Básica (SAEB). 20 I 8. Disponível em: http://portal.inep.gov.br/educacao-basica/saeb. Acesso em: 02 nov. 2018.

BRASIL. Programa Dinheiro Direto na Escola (PDDE). 20 I 8. Disponível em: https://www.fnde.gov.br/pls/internet_pdde/internet_fnde.pdderex_2_pc. Acesso em: 04 out. 2018.

CASTRO, M. H. G. Sistemas de avaliação da educação no Brasil: avanços e novos desafios. São Paulo em Perspectiva. São Paulo, Fundação Sead, v. 23, n. I , p. 5-18, jan./jun. 2009. Disponível em: http://www.sead.gov.br. Acesso em 15 nov. 2018.

FERNANDES, Reynaldo. Índice de Desenvolvimento da Educação Básica (Ideb) / Reynaldo Fernandes. Brasília : Instituto Nacional de Estudos e Pesquisas Educacionais Anísio Teixeira, 2007.

GARCIA, Maria Virgínia Morais. Proposição de um guia de gestão de resultados de avaliações externas. Florianópolis: Universidade Federal de Santa Catarina, 2017. 164 pgs. Dissertação (Mestrado Profissional) - Universidade Federal de Santa Catarina, Centro Tecnológico, Programa de PósGraduação em Métodos e Gestão em Avaliação. Florianópolis, 2017.

LIBÂNEO, José Carlos. Organização e gestão da escola: teoria e prática. $5^{a}$ ed. Goiânia: MF Livros, 2008.

PARO, Vitor Henrique. Reprovação escolar: renúncia à educação. São Paulo: Xamã, 200 I .

PARO, Vitor Henrique. Gestão escolar, democracia e qualidade do ensino. São Paulo: Ática, 2007.

RIGOTTI, José Irineu Rangel; CERQUEIRA, Cézar Augusto. As bases de dados do INEP e os indicadores educacionais: conceitos e aplicações. In: RIOS-NETO, Eduardo Luís Gonçalves; RIANI, Juliana de Lucena Ruas. (Org.). Introdução à demografia da educação. Campinas: ABEP, 2004, v. I , p. 73-88. 
SOARES, José Francisco; XAVIER, Flávia. Pressupostos educacionais e estatísticos do Ideb. In: Educação \& Sociedade, v. 34, n. 124, 2013. 